\title{
Porous and Cross-Linked Cellulose Beads for Toxic Metal Ion Removal: Hg(II) Ions
}

\author{
Renuka R. Gonte, K. Balasubramanian, and Jyothi D. Mumbrekar \\ Department of Materials Engineering, Defence Institute of Advanced Technology (DU), Girinagar, Pune 411025, India \\ Correspondence should be addressed to K. Balasubramanian; balask@diat.ac.in
}

Received 25 March 2013; Revised 29 July 2013; Accepted 10 August 2013

Academic Editor: Ridvan Say

Copyright ( 2013 Renuka R. Gonte et al. This is an open access article distributed under the Creative Commons Attribution License, which permits unrestricted use, distribution, and reproduction in any medium, provided the original work is properly cited.

\begin{abstract}
Mercury is a highly toxic and hazardous pollutant even in trace quantity which poses a major threat to the ecosystem on deposition in the environment. Removal of mercury from aqueous systems has been a subject of immense interest for researchers. The synthesis of highly cross-linked cellulose beads embedded with ferric oxide for removal of $\mathrm{Hg}$ (II) ions from aqueous systems has been investigated. The beads were synthesized by solution polymerization technique. The impact of solution $\mathrm{pH}$, ferric oxide content, and initial concentration of $\mathrm{Hg}$ (II) ions on the uptake of $\mathrm{Hg}$ (II) ions revealed that maximum adsorption occurs at $\mathrm{pH} 6.0$ with beads having $10 \mathrm{wt} \% \mathrm{Fe}_{2} \mathrm{O}_{3}$ content. Equilibrium adsorption of $\mathrm{Hg}$ (II) ions followed the Langmuir isotherm model. Adsorption was observed to follow pseudo second-order kinetic model and intraparticle diffusion model.
\end{abstract}

\section{Introduction}

Heavy metals such as mercury are considered as toxic and their accumulation over the period of time in human bodies causes serious health hazards, possessing major threats to human health. Heavy metal pollution can arise from various sources but is highly common from purification of metals, for example, smelting of copper and preparation of nuclear fuels. Unlike organic pollutants, heavy metals do not biodegrade which is the largest problem associated with the persistence of heavy metals which has the potential of bioaccumulation and biomagnification entering the food chain causing heavier exposure and hence biological disorders. Mercury affects the central nervous system, kidneys [1], and liver. Compared to other heavy metals, mercury even at low concentrations is highly neurotoxic [2].

Various conventional methods such as chemical precipitation, membrane filtration, ion exchange, lime softening, coagulation-flocculation, photoreduction $[1,3,4]$, and electrochemical treatment have been employed for removal of mercury from aqueous systems. Adsorption is the most effective technique for removing heavy metal ions from aqueous solutions. The important aspect of the adsorption process is easy regeneration ability and less operational cost, simple design, easy operation, and free or less generation of toxic substances [5]. Adsorption techniques have proven successful in removing colored organic species and the choice of the adsorbent is one of the key factors determining the effectiveness of any adsorption process. The adsorption process at solid/liquid interface has been extensively employed for several reasons, mainly due to its efficiency and economy [6]. Physical adsorption because of its low cost, high efficiency, easy handling, wide variety of adsorbents and high stabilities toward the adsorbents has become the most widely used method for the elimination of heavy metal ions from wastewater. Adsorption of mercury ions onto various natural substrates like saw dust, banana stalk, coconut coir, and so forth, has been extensively studied [7-9]. Modified cellulose substrates used for adsorption of mercury. Porous cellulose modified with polyethyleneimine for removal of mercury from wastewater was reported by Navarro et al. [10]. Poly(glycidylmethacrylate-meth-yl-methacrylate-ethyleneglycoldimethacrylate) magnetic beads were used for the removal of mercury(II) ions from aqueous solutions by Bayramoğlu and Arica [11].

In this study, we report a simple, cost-effective technique for removal of $\mathrm{Hg}(\mathrm{II})$ ions from aqueous systems. The adsorbate was synthesized using cellulose acetate beads embedded 
with $\mathrm{Fe}_{2} \mathrm{O}_{3}$. The impact of solution $\mathrm{pH}, \mathrm{Fe}_{2} \mathrm{O}_{3}$ content in the beads, and initial metal ion concentration was studied and optimized experimental parameters were obtained. Further experiments were performed under these optimized parameters and the obtained data was used to validate the adsorption isotherm models and adsorption kinetics. The thermodynamic aspect of the adsorption was studied to understand the feasibility of the process.

\section{Experimental}

2.1. Materials and Methods. Cellulose acetate, ferric oxide, epichlorohydrin, sodium chloride $(\mathrm{NaCl})$, sodium hydroxide $(\mathrm{NaOH})$, hydrochloric acid $(\mathrm{HCl})$, dimethylsulphoxide (DMSO), mercury chloride $\left(\mathrm{HgCl}_{2}\right)$, potassium iodide (KI), rhodamine $\mathrm{B}$, and sulphuric acid $\left(\mathrm{H}_{2} \mathrm{SO}_{4}\right)$ were all purchased from Merck Inc., India, and used as received. Deionized water was used for all experimental work.

2.2. Synthesis of Ferric Oxide Embedded Cellulose Acetate Beads. The ferric oxide loaded cellulose acetate beads were synthesized by solution polymerization technique $[12,13]$. Briefly, varying concentrations of ferric oxide (1-20 wt\%) were sonicated in DMSO for $15 \mathrm{~min}$ and calculated amount of cellulose acetate, epichlorohydrin, and $\mathrm{NaHCO}_{3}$ was added to this solution and stirred till the solution became homogeneous. This mixture was precipitated in an acid coaggulation bath containing $0.1 \mathrm{M} \mathrm{HCl}$. The beads obtained were filtered, washed with deionized water, hydrolyzed in $0.1 \mathrm{M} \mathrm{NaOH}$, finally washed with deionised water, and air-dried at room temperature to constant weight.

2.3. Adsorption Studies. Batch adsorption studies were carried out to investigate the effect of $\mathrm{pH}$ of solution and $\mathrm{Fe} 2 \mathrm{O} 3$ content in the beads on adsorption of $\mathrm{Hg}(\mathrm{II})$ ions. Briefly, requisite amount of adsorbents and adsorbate were agitated for predetermined time intervals on a mechanical shaker at $720 \mathrm{rpm}$, and supernatant solution was filtered and analyzed for concentration of $\mathrm{Hg}(\mathrm{II})$ ions by complexing with the rhodamine $B$ [14]. The change in concentration was monitored periodically using Nanodrop UV-Visible Spectrophotometer (NANO DROP, ND-1000). The amount of $\mathrm{Hg}(\mathrm{II})$ ions adsorbed $(q)$ was calculated as follows [13]:

$$
q=\frac{C_{o}-C_{e}}{w} * V .
$$

The adsorption efficiency was calculated as [13]

$$
\% \mathrm{Ad}=\frac{C_{o}-C_{e}}{C_{o}} * 100,
$$

where $C_{o}$ and $C_{e}$ are the initial and equilibrium concentration of $\mathrm{Hg}$ (II) ions (mg/L), respectively, $w$ is the amount of the adsorbent used, and $V$ is the total volume of the metal ion solution.

All the experiments were repeated thrice to validate the repeatability of the results. The results presented are the average of all the three experiments conducted.

\section{Results and Discussion}

The $\mathrm{Fe}_{2} \mathrm{O}_{3}$ loaded cellulose acetate beads of uniform diameter $0.5 \mathrm{~cm}$ (Figure 1(a)) were synthesized during the precipitation polymerization method. The optical image analyzer and scanning electron microscopy (Jeol JSM-840 A) were used to examine the surface morphology of the beads. The optical image of beads shows the presence of porous surface structure (Figure 1(b)) which is supported by the SEM images confirming the existence of highly micro/macro structure. The SEM micrographs also revealed the presence of large number of micropores $(1-25 \mu \mathrm{m})$, voids, and well-defined flow lines as can be observed from Figure 1(c) indicating presence of capillary action. The presence of mercury in the beads after adsorption was confirmed from the EDX pattern (Figure 1(d)). The surface porosity calculated as from the SEM images per ASTM B 276 standard [15] was found to be $13.1 \%$.

3.1. Effect of $p H$. The adsorption of $\mathrm{Hg}$ (II) ions onto the beads was studied in the $\mathrm{pH}$ range 3-8 at a constant volume. Maximum adsorption was observed at $\mathrm{pH}$ 6. The variation in adsorption with $\mathrm{pH}$ of the solution is depicted in Figure 2(a). According to the stability constant calculations, in the presence of $\mathrm{Cl}^{-}$ions, the predominant species at $\mathrm{pH}<4$ is $\mathrm{HgCl}_{2}$. This prevents the binding of $\mathrm{Hg}$ (II) ions onto the sorbent as chloride ions tend to form more stable complexes with $\mathrm{Hg}$ (II) such as $\mathrm{HgCl}_{2},\left(\mathrm{HgCl}_{3}\right)^{-}$, and $\left(\mathrm{HgCl}_{4}\right)^{2-}$ [16]. Also at low $\mathrm{pH}$, the excess $\mathrm{H}^{+}$ions present in the solution compete with $\mathrm{Hg}(\mathrm{II})$ ions for active sites present on the beads decreasing the adsorption of $\mathrm{Hg}(\mathrm{II})$ ions. However, at $\mathrm{pH} 6.0$ the predominant species is $\mathrm{Hg}(\mathrm{OH})_{2}$ in the medium and the protonation of the beads is minimum leading to the increased adsorption of $\mathrm{Hg}$ (II) ions. It was observed that at higher $\mathrm{pH}$ values, a slight decrease in the adsorption was noted since the metal ions tend to form insoluble hydroxides.

3.2. Effect of Varying $\mathrm{Fe}_{2} \mathrm{O}_{3}$ Content in the Beads. The effect of varying the concentration of $\mathrm{Fe}_{2} \mathrm{O}_{3}$ in beads on adsorption of $\mathrm{Hg}$ (II) ions was studied by varying the $\mathrm{Fe}_{2} \mathrm{O}_{3}$ content from 0 to $20 \mathrm{wt} \%$. Results indicate that adsorption increases with increasing the $\mathrm{Fe}_{2} \mathrm{O}_{3}$ content up to $10 \mathrm{wt} \%$ which is correlated to the degree of dispersion of $\mathrm{Fe}_{2} \mathrm{O}_{3}$ in the polymer matrix. Further increase in $\mathrm{Fe}_{2} \mathrm{O}_{3}$ content results in agglomeration of the particles which causes steric hindrance for adsorption of $\mathrm{Hg}(\mathrm{II})$ ions.

3.3. Effect of Hg(II) Ion Concentration. The graph of adsorption as a function of initial $\mathrm{Hg}$ (II) ion concentration (Figure 2(c)) reveals that the extent of adsorption decreases with increasing the $\mathrm{Hg}(\mathrm{II})$ concentration. As a rule, increasing the initial metal ion concentration results in an increase in the adsorption capacity since it provides a driving force to overcome all mass transfer resistances of the metal ions between the aqueous and solid phase. However, the sorption efficiency decreases since the adsorbent has a limited number of active sites, which saturates after a certain concentration. This indicates that the adsorption capacity will increase with the increase of initial concentration mainly due to the rise 


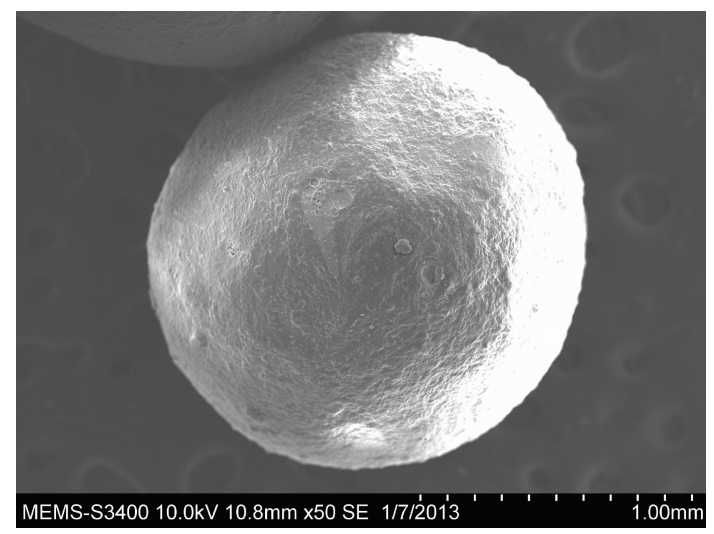

(a)

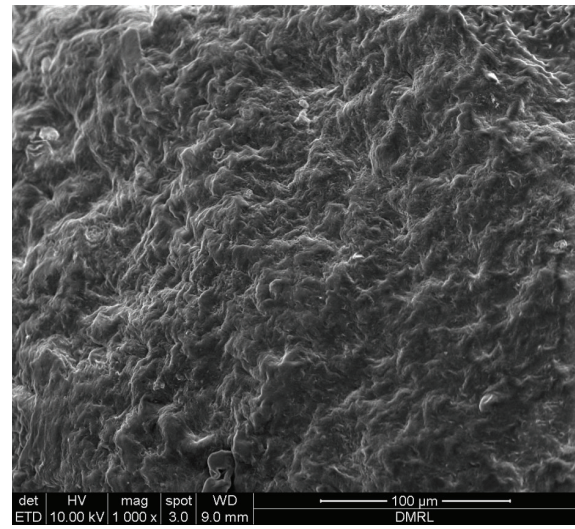

(c)

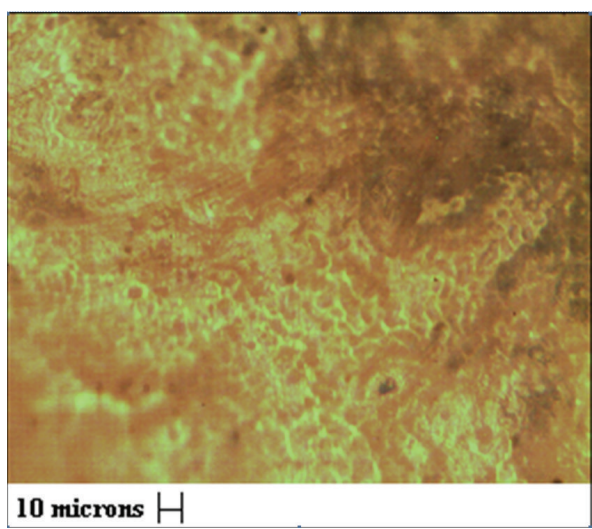

(b)

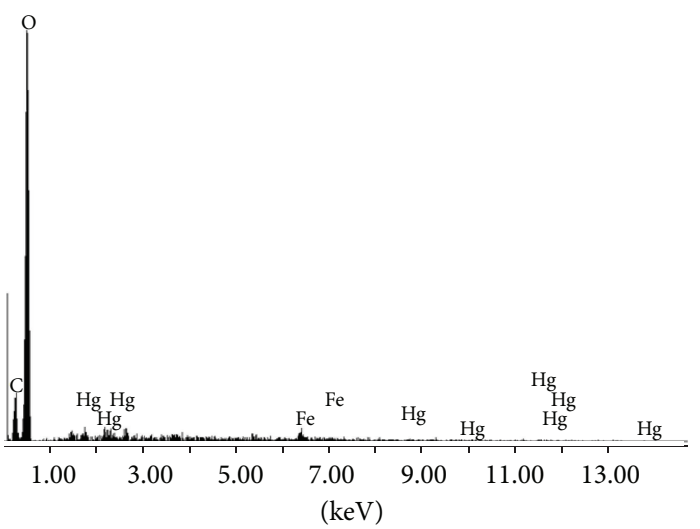

(d)

Figure 1: (a) SEM image; (b) optical image; (c) magnified surface SEM image; (d) EDX pattern of beads.

in the mass transfer from the concentration gradient. However, the concentration will inversely impact the adsorption efficiency because of the limited adsorption sites available for uptake of metal ions [17].

3.4. Equilibrium Adsorption Isotherms. Adsorption isotherm studies are important to determine the efficiency of adsorption. These isotherms indicate the distribution of adsorbate between liquid and solid phase when equilibrium state was achieved. Analysis of the isotherm data by fitting them to different isotherm models is an important step to find the suitable model that can be used for design purpose [17]. The isotherm constants were obtained by linear regression methods and are presented in Table 1.

3.4.1. Langmuir Isotherm Model. The Langmuir isotherm model assumes monomolecular layer adsorption on homogenous surface without any interactions between the adsorbed molecules [18]:

$$
q_{e}=\frac{q_{\max } * K_{L} * C_{e}}{1+\left(K_{L} * C_{e}\right)}
$$

where $C_{e}$ is the equilibrium concentration, $q_{e}$ is the amount of metal ions adsorbed at equilibrium (mg/g), $q_{\max }$ is $q_{e}$ for a complete monolayer $(\mathrm{mg} / \mathrm{g})$, and $K_{L}$ is Langmuir adsorption constant which is a function of free energy of adsorption $(\mathrm{L} / \mathrm{mg})$. The linearized form of the Langmuir equation is

$$
\frac{C_{e}}{q_{e}}=\frac{1}{q_{\max } * K_{L}}+\frac{C_{e}}{q_{\max }} .
$$

To examine the progression of adsorption process, the dimensionless constant, separation factor, $R_{L}$, for Langmuir isotherm is calculated using the below equation:

$$
R_{L}=\frac{1}{1+\left(K_{L} * C_{o}\right)} \text {. }
$$

The value of $R_{L}$ suggests whether the adsorption is irreversible $\left(R_{L}=0\right)$, favorable $\left(0<R_{L}<1\right)$, linear $\left(R_{L}=1\right)$, or unfavorable $\left(R_{L}>1\right)$. The regression coefficient value (0.9454) (Figure 3(a)) and the calculated $R_{L}$ value (0.32) indicate favourable adsorption.

3.4.2. Freundlich Isotherm Model. The Freundlich isotherm assumes that adsorption process occurs on heterogeneous 
TABLE 1: Equilibrium adsorption parameters.

\begin{tabular}{|c|c|c|}
\hline Adsorption isotherm models & Different isotherm parameters & Values of isotherm parameters \\
\hline \multirow{4}{*}{ Langmuir } & $q_{\max }\left(\mathrm{mg} \mathrm{g}^{-1}\right)$ & 18.92 \\
\hline & $K_{L}\left(\mathrm{~L} \mathrm{mg}^{-1}\right)$ & 0.018 \\
\hline & $R_{L}$ & 0.32 \\
\hline & $R$ & 0.9454 \\
\hline \multirow{3}{*}{ Freundlich } & $K_{F}$ & 0.72 \\
\hline & $n$ & 1.59 \\
\hline & $R$ & 0.9160 \\
\hline \multirow{4}{*}{ Dubinin-Radushkevich (D-R) } & $q_{\max }\left(\operatorname{molg}^{-1}\right)$ & 12.94 \\
\hline & $K_{D}\left(\mathrm{~mol}^{2} \mathrm{~J}^{-2}\right)$ & $-5.5 \times 10^{-5}$ \\
\hline & $\varepsilon$ & 77.67 \\
\hline & $R$ & 0.9999 \\
\hline
\end{tabular}

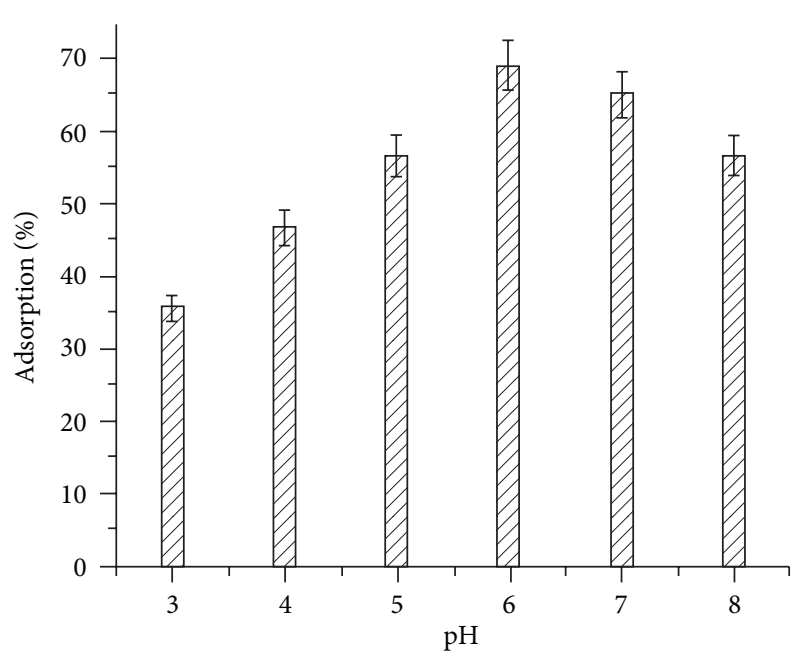

(a)

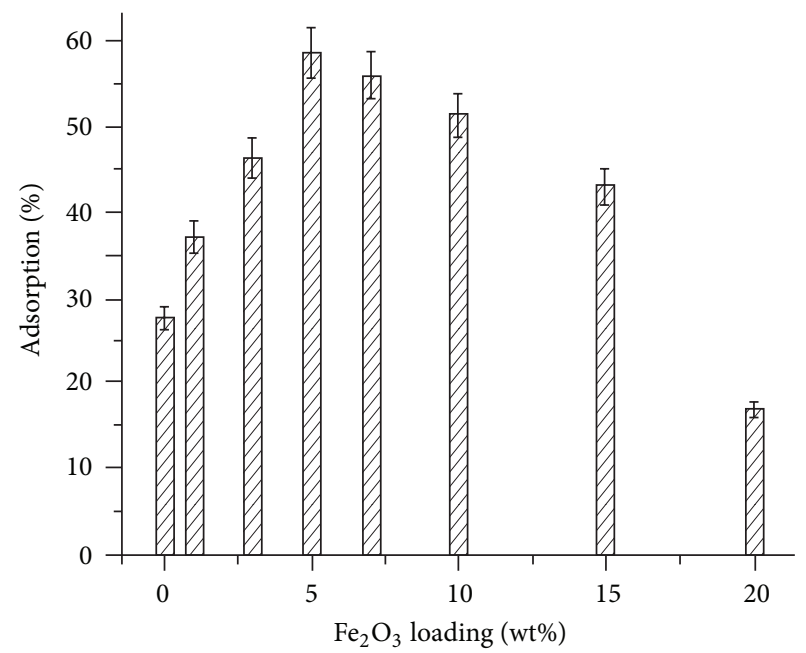

(b)

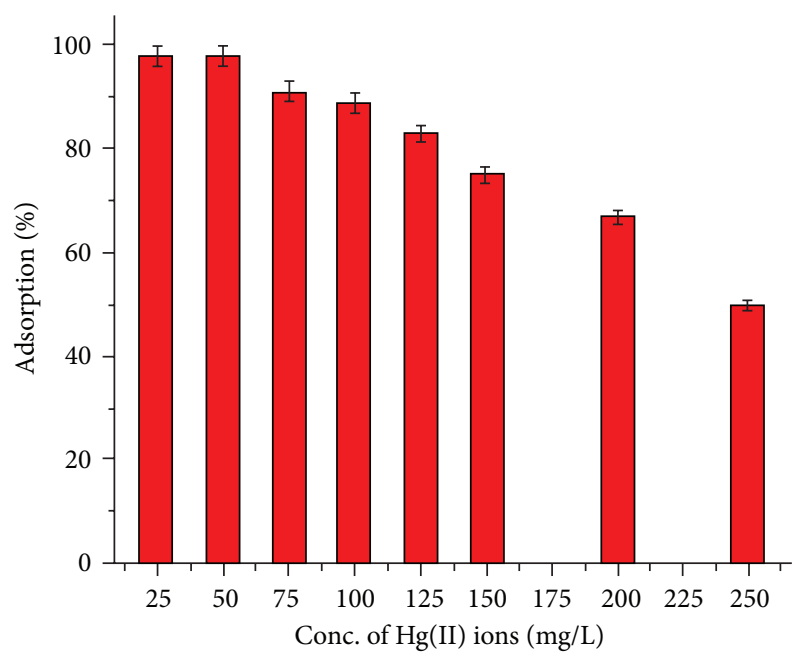

(c)

Figure 2: Effect of (a) pH and (b) ferric oxide concentration on adsorption on $\mathrm{Hg}(\mathrm{II})$ ions; (c) initial $\mathrm{Hg}$ (II) ion conc. 


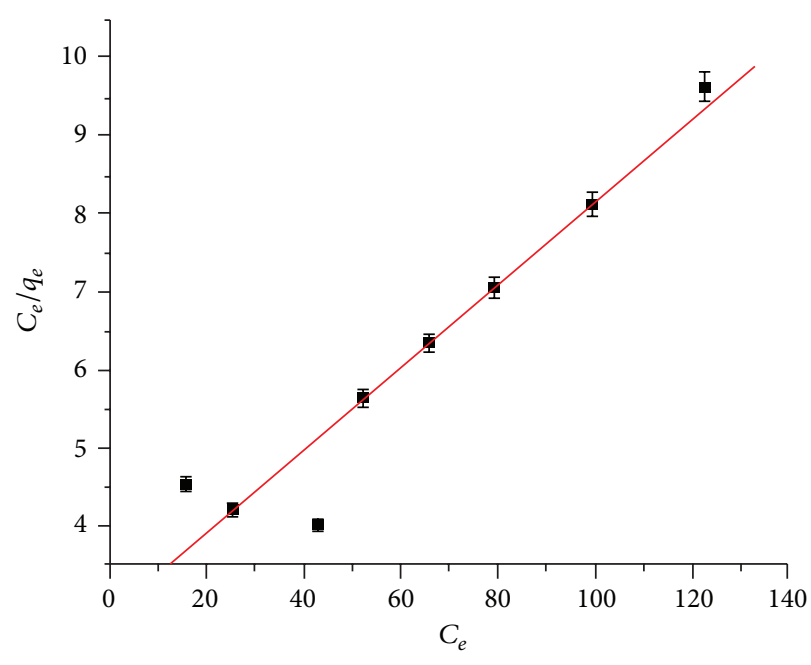

(a)

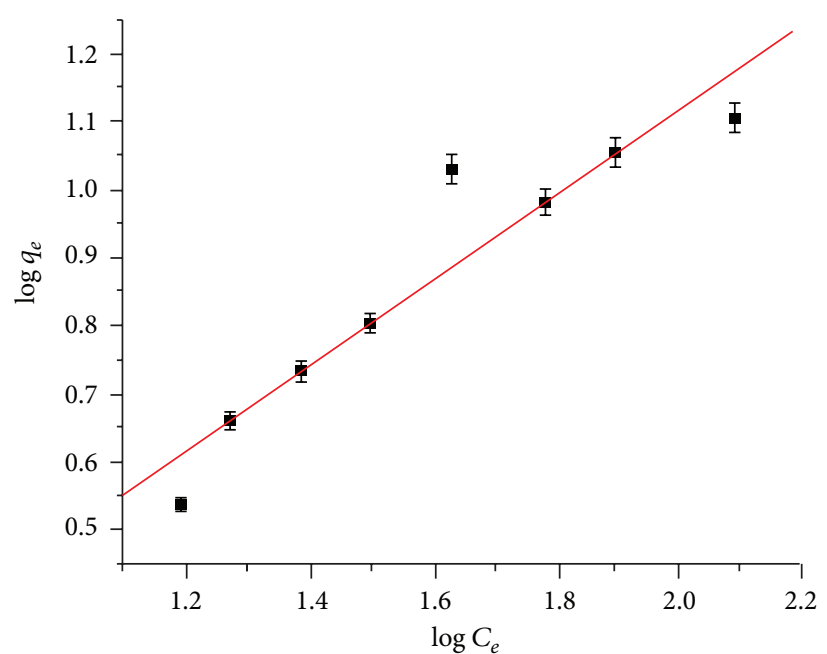

(b)

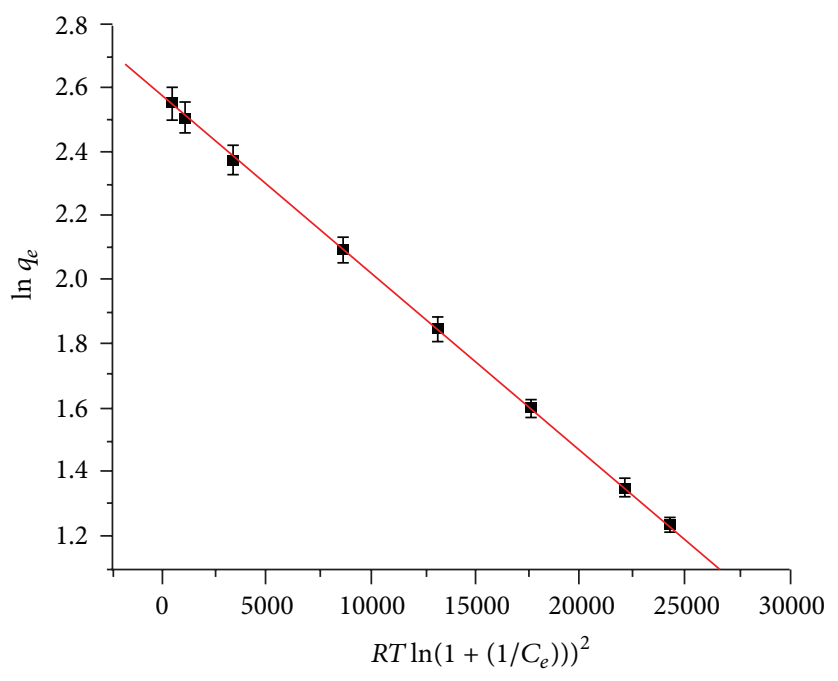

(c)

FIGURE 3: Equilibrium adsorption: (a) Langmuir, (b) Freundlich, and (c) D-R.

surfaces and relates the concentration of metal ions at equilibrium to the adsorption capacity. This model is applicable to multilayer physisorption processes [17]. This model is defined by the equation below:

$$
q_{e}=\left(K_{F} * C_{e}\right)^{1 / n},
$$

where $K_{F}$ and $n$ are the Freundlich constants related to adsorption capacity and adsorption intensity, respectively. The linearized form of this equation is written as

$$
\log q_{e}=\frac{1}{n}\left(\log C_{e}\right)+\log K_{F} .
$$

A plot of $\log q_{e}$ versus $\log C_{e}$ yields the constants $n$ and $K_{F}$ from its slope and intercept, respectively, as shown in Figure 3(b). The value of $n>1$ indicates favourable adsorption; larger value of $n$ ( 1 to 10 ) indicates strong interaction between adsorbent and adsorbate. The $n$ value obtained using these beads is 1.59 which indicates favourable chemical interactions between the adsorbent and $\mathrm{Hg}(\mathrm{II})$ ions.

3.4.3. Dubinin-Radushkevich (D-R) Isotherm. DubininRadushkevich (D-R) isotherm assumes that the porosity of the adsorbent has an effect on the adsorption process [19]. Dubinin suggested the isotherm to estimate the mean free energy of adsorption which is given by the equation

$$
q_{e}=q_{\max } * \exp \left(-K_{D} \varepsilon^{2}\right) .
$$

The linearized form of the above equation is given as

$$
\ln q_{e}=\ln q_{\max }-K_{D}[\varepsilon]^{2},
$$


where $K_{D}\left(\mathrm{~mol}^{2} \mathrm{~kJ}^{-2}\right)$ is D-R model constant related to the mean adsorption energy and $\varepsilon$ is Polanyi potential given by

$$
\varepsilon=R T \ln \left(1+\frac{1}{C_{e}}\right),
$$

where $R$ is the gas constant $\left(\mathrm{kJ} \mathrm{mol}^{-1} \mathrm{~K}^{-1}\right)$ and $T$ is the absolute temperature $(\mathrm{K})$.

The plot for D-R model yields high correlation coefficient values (Figure 3(c)) confirming the applicability of this model.

According to the above results, it is predicted that the initial monolayer adsorption occurs (as confirmed from Langmuir model) leading to further multilayered chemical interactions between the $\mathrm{Hg}$ (II) ions and the beads as explained by the Freundlich isotherm. The effect of porosity of the adsorbent on the process of adsorption is explained by the Dubinin-Radushkevich isotherm model.

3.5. Kinetic Studies. Adsorption kinetics have been thoroughly investigated to predict the adsorption mechanism and rate determining step. The knowledge of adsorption mechanism and rate limiting steps is applicable in selecting optimum conditions for large scale applications.

3.5.1. Pseudo Second-Order Model. The pseudo second-order model considers that the rate is directly proportional to the number of active sites present on the adsorbent surface [17, $20,21]$ and the amount of metal ions adsorbed onto the surface of the adsorbent at time $t$ and the amount of metal ions adsorbed at equilibrium. The pseudo second-order equation is given as

$$
\frac{t}{q_{t}}=\frac{1}{k_{2} * q_{e}}+\frac{1}{q_{e}} * t,
$$

where $k_{2}\left(\mathrm{~g} \mathrm{mg}^{-1} \mathrm{~min}^{-1}\right)$ is the pseudo second-order rate constant.

The linear plots for $t / q_{t}$ versus $t$ with high correlation coefficient values indicates pseudo second-order kinetics for adsorption of $\mathrm{Hg}(\mathrm{II})$ ions as shown in Figure 4(a).

3.5.2. Pseudo First-Order Model. Lagergren demonstrated that the rate of adsorption of solute onto the adsorbent depends on the adsorption capacity and follows the pseudo first-order rate equation which is used to estimate the $k_{\text {ad }}$, the mass transfer coefficient. This model is used to describe the kinetics of solid-liquid phase adsorption [17]:

$$
\frac{\mathrm{d} q_{t}}{\mathrm{~d} t}=k_{p 1}\left(q_{e}-q_{t}\right)
$$

The above equation is integrated with boundary conditions, $q_{t}=0$ at $t=0$, and $q_{t}=q_{t}$ at $t=t$ and rearranged to get

$$
\log \left(q_{e}-q_{t}\right)=\log q_{e}-\frac{k_{p 1}}{2.303} * t,
$$

where $k_{p 1}$ is the pseudo- first-order adsorption rate constant $\left(\min ^{-1}\right)$.
The straight line plot with negative slope suggests the applicability of pseudo first-order kinetic model as evident from Figure 4(b). However, low $R^{2}$ values indicate poor fit of this model to the adsorption $\mathrm{Hg}$ (II) ions.

3.5.3. Intraparticle Diffusion Model. The rate limiting step, which is governed by adsorption mechanism, is a significant factor in determining the mechanism of the adsorption process. This information is useful in optimizing conditions for large scale adsorption processes. To understand this usually intraparticle diffusion model is used. For a solid-liquid adsorption process, the solute transfer usually occurs by external mass transfer (boundary layer diffusion), intraparticle diffusion (pore diffusion), or both [17]. According to Weber and Morris, the intraparticle diffusion coefficient $k_{\text {int }}$ is given by the equation

$$
q_{t}=k_{\mathrm{int}} * t^{1 / 2}
$$

where $k_{\text {int }}$ is the intraparticle diffusion rate constant $\left(\mathrm{mg} \mathrm{g}^{-1}\right.$ $\left.\min ^{1 / 2}\right)$.

The plot of $q_{t}$ versus $t^{1 / 2}$ does not pass through the origin and shows multilinearity indicating that but not only intraparticle diffusion, but some other processes are also involved in the adsorption process. The first sharper portion indicates instantaneous adsorption of $\mathrm{Hg}$ (II) ions on the external surface of the beads from the bulk of the solution which is due to boundary layer diffusion. Value of I indicates thickness of the boundary layer. The second portion is the gradual adsorption stage with controlled intraparticle or pore diffusion where $\mathrm{Hg}$ (II) ions move into the interior of the beads. The third step indicates the attainment of equilibrium stage where intraparticle diffusion starts to slow down due to very low concentration of $\mathrm{Hg}$ (II) ions in the solution [17]. The intraparticle diffusion rate is obtained from the slope of the gentle-sloped portion of the graph. The graph presents a three-stage adsorption process as can be observed from Figure 4(c).

The kinetic results suggest that the adsorption data of $\mathrm{Hg}$ (II) ions from aqueous solution using these cellulose acetate beads gives satisfactory fit for pseudo second-order and intraparticle diffusion models. High $R^{2}$ values for these kinetic models suggest that the adsorption of $\mathrm{Hg}$ (II) ions can be well explained by these models. The pseudo second-order rate equation suggests the presence of numerous active sites on adsorbent surface. The multilinear graphs obtained for the intraparticle diffusion model confirm that initially there will be an instantaneous adsorption of $\mathrm{Hg}$ (II) ions onto the surface of the adsorbent system through surface diffusion. With increase in surface coverage there is a gradual adsorption through controlled intraparticle or pore diffusion where $\mathrm{Hg}$ (II) ions move into the interior of the beads and at a later stage when the equilibrium is reached the intraparticle diffusion starts to slow down. Various kinetic parameters calculated from different kinetic models are summarized in Table 2.

3.6. Thermodynamic Studies. The thermodynamic parameter, Gibb's free energy change $\left(\Delta G^{\circ}\right)$ is essential to know 
TABLE 2: Kinetic parameters.

\begin{tabular}{lccccc}
\hline \multirow{2}{*}{ Conc. (mg/L) } & \multicolumn{2}{c}{ Pseudo second-order } & \multicolumn{2}{c}{ Pseudo second-order } & \multicolumn{2}{c}{ Intraparticle diffusion } \\
& $k_{p 2} \times 10^{-4}$ & $R^{2}$ & $k_{p 1} \times 10^{-3}$ & $R^{2}$ & Kint \\
\hline 50 & 38.93 & 0.9698 & -8.71 & 0.8496 & 0.25 \\
150 & 5.93 & 0.9151 & -20.13 & 0.9328 & 0.95 \\
250 & 5.89 & 0.9989 & -0.69 & 0.7730 & 0.21 \\
\hline
\end{tabular}

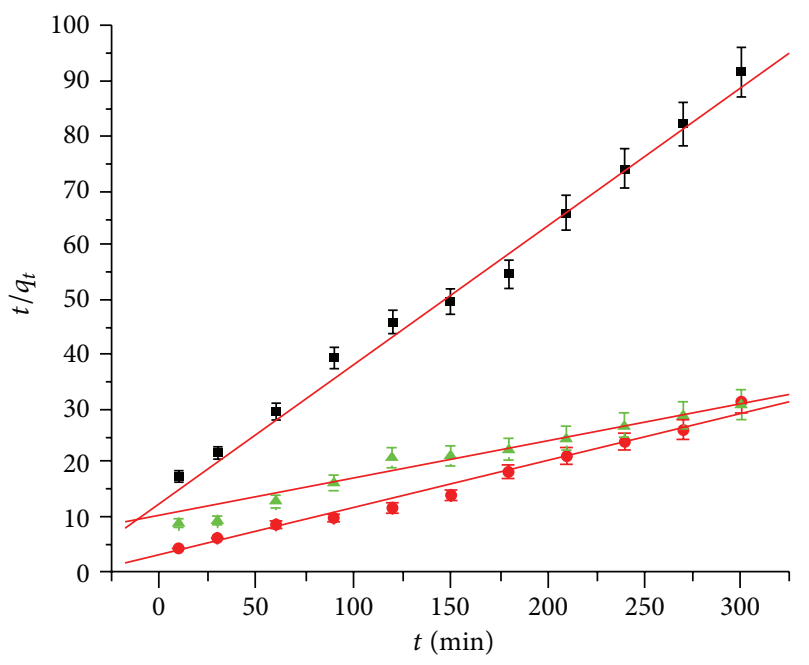

- $50 \mathrm{mg} / \mathrm{L}$

- $150 \mathrm{mg} / \mathrm{L}$

$\Delta 250 \mathrm{mg} / \mathrm{L}$

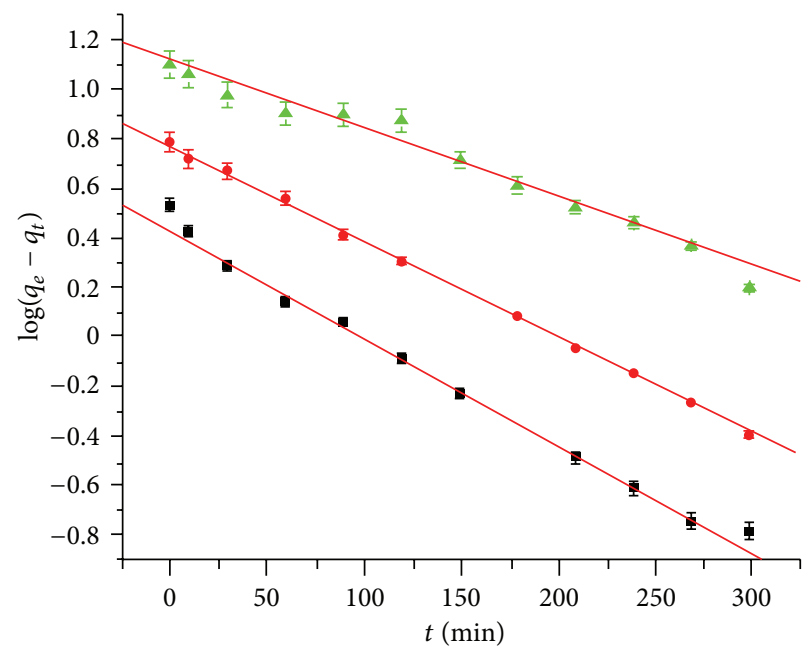

- $50 \mathrm{mg} / \mathrm{L}$

- $150 \mathrm{mg} / \mathrm{L}$

$\Delta 250 \mathrm{mg} / \mathrm{L}$

(a)

(b)

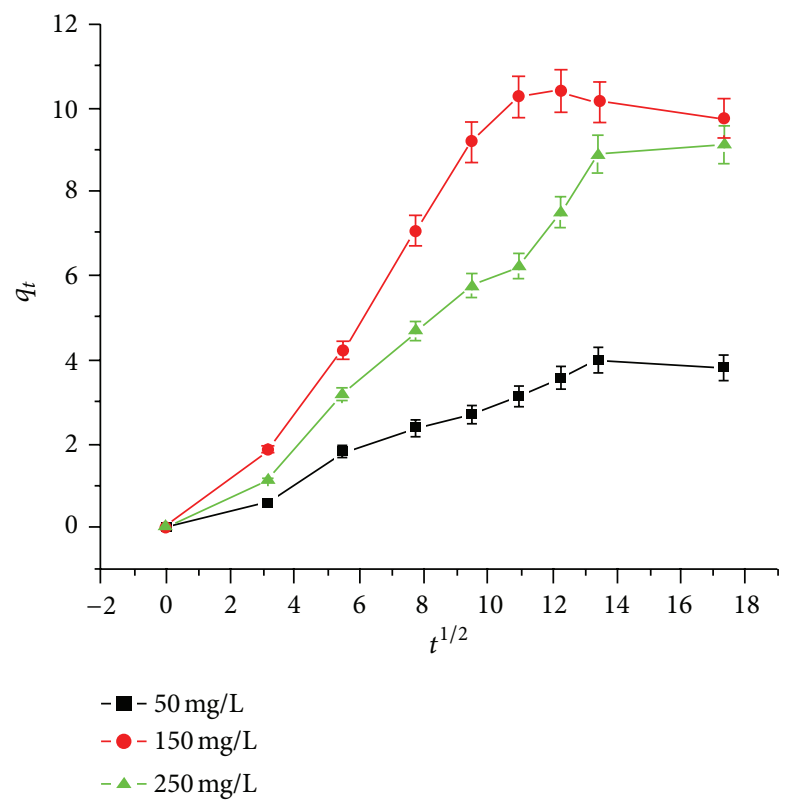

(c)

FIGURE 4: Kinetic models: (a) pseudo second-order (b) pseudo first-order (c) intraparticle diffusion. 
the spontaneity of the adsorption process. The adsorption of $\mathrm{Hg}$ (II) ions onto cellulose beads loaded with ferric oxide was studied at a temperature of $298 \mathrm{~K}$. The free energy for adsorption $\left(\Delta G^{\circ}\right)$ was calculated from the equation

$$
\Delta G^{\circ}=-R T \ln K_{L}
$$

where $K_{L}$ is the equilibrium constant obtained from Langmuir isotherm $[17,21], R$ is universal gas constant (8.314 $\mathrm{Jmol}^{-1} \mathrm{~K}^{-1}$ ), and $T$ is absolute temperature $(\mathrm{K})$. The change in free energy $\left(\Delta G^{\circ}\right)$ value obtained for uptake of $\mathrm{Hg}$ (II) ions is $-9.89 \mathrm{~kJ} \mathrm{~mol}^{-1}$. The negative value obtained establishes the feasibility of adsorption and confirms the spontaneity of the adsorption process.

\section{Conclusion}

The naturally abundant material, cellulose, is used to synthesize polymer beads using a simple, easy, and less energy consuming procedure using dimethylsulphoxide as solvent. The adsorption capacity of the beads was enhanced by embedded $\mathrm{Fe}_{2} \mathrm{O}_{3}$ and used to remove $\mathrm{Hg}$ (II) ions from aqueous systems. Maximum adsorption occurred at $\mathrm{pH}$ 6.0, and using beads loaded with $10 \mathrm{wt} \%$ of $\mathrm{Fe}_{2} \mathrm{O}_{3}$. The experimental adsorption data fitted well with Langmuir, Freundlich, and $\mathrm{D}-\mathrm{R}$ equilibrium isotherm models indicating that initial monolayer adsorption occurs leading to further multilayered chemical interactions between the $\mathrm{Hg}$ (II) ions and the beads. The kinetic studies suggested pseudo second-order and intraparticle diffusion playing a key role in the adsorption process. The key advantage of the system is that it exhibits equal potential when used in batch adsorption process as well as continuous flow process. The adsorbents can be shaped in various forms such as thin films, membranes, and beads, which provides additional application oriented advantage. This adsorbents can find good applications in industrial effluent treatment processes. The cost effectiveness of this technique makes it more feasible for the large scale use.

\section{Acknowledgments}

The authors would like to thank Dr. Prahlada, Vice Chancellor, DIAT(DU), for his support and encouragement in this research activity. The authors would also like to thank Dr. Partha Ghosal, Sc'E', DMRL Hyderabad, for SEM images.

\section{References}

[1] J. N. Bhakta and Y. Munekage, "Mercury(II) adsorption onto the magnesium oxide impregnated volcanic ash soil derived ceramic from aqueous phase," International Journal of Environmental Research, vol. 5, no. 3, pp. 585-594, 2011.

[2] M. Aschner and J. L. Aschner, "Mercury neurotoxicity: mechanisms of blood-brain barrier transport," Neuroscience and Biobehavioral Reviews, vol. 14, no. 2, pp. 169-176, 1990.

[3] H. Agarwal, D. Sharma, S. K. Sindhu, S. Tyagi, and S Ikram, "Removal of mercury from wastewater use of green adsorbents-a review," Electronic Journal of Environmental, Agricultural and Food Chemistry, vol. 9, no. 9, pp. 1551-1558, 2010.

[4] X.-W. Wu, H.-W. Ma, J.-H. Li, J. Zhang, and Z.-H. Li, "The synthesis of mesoporous aluminosilicate using microcline for adsorption of mercury(II)," Journal of Colloid and Interface Science, vol. 315, no. 2, pp. 555-561, 2007.

[5] E. Khan, M. Li, and C. P. Huang, "Hazardous waste treatment technologies," Water Environment Research, vol. 80, no. 10, pp. 1654-1708, 2008.

[6] A. Gürses, Ç. Doğar, M. Yalçin, M. Açikyildiz, R. Bayrak, and S. Karaca, "The adsorption kinetics of the cationic dye, methylene blue, onto clay," Journal of Hazardous Materials, vol. 131, no. 1-3, pp. 217-228, 2006.

[7] A. K. Meena, G. K. Mishra, S. Kumar, C. Rajagopal, and P. N. Nagar, "Low-cost adsorbents for the removal of mercury (II) from aqueous solution-a comparative study," Defence Science Journal, vol. 54, no. 4, pp. 537-548, 2004.

[8] I. G. Shibi and T. S. Anirudhan, "Synthesis, characterization, and application as a mercury(II) sorbent of banana stalk (Musa paradisiaca)-polyacrylamide grafted copolymer bearing carboxyl groups," Industrial and Engineering Chemistry Research, vol. 41, no. 22, pp. 5341-5352, 2002.

[9] Y. Yadav, M. Pakhmore, M. Arsalaan, and S. J. Purohit, "Bioadsorption of $\mathrm{Hg}(\mathrm{II})$ ions from waste water using coconut coir," International Journal of Engineering Research and Technology, vol. 4, no. 1, pp. 1-8, 2011.

[10] R. R. Navarro, K. Sumi, N. Fujii, and M. Matsumura, "Mercury removal from wastewater using porous cellulose carrier modified with polyethyleneimine," Water Research, vol. 30, no. 10, pp. 2488-2494, 1996.

[11] G. Bayramoğlu and M. Y. Arica, "Kinetics of mercury ions removal from synthetic aqueous solutions using by novel magnetic p(GMA-MMA-EGDMA) beads," Journal of Hazardous Materials, vol. 144, no. 1-2, pp. 449-457, 2007.

[12] Y.-X. Bai and Y.-F. Li, "Preparation and characterization of crosslinked porous cellulose beads," Carbohydrate Polymers, vol. 64, no. 3, pp. 402-407, 2006.

[13] A. Ayalew, R. R. Gonte, and K. Balasubramanian, "Development of polymer composite beads for dye adsorption," International Journal of Green Nanotechnology, vol. 4, no. 4, pp. 440-454, 2012.

[14] A. Y. Y. Loo, Y. P. Lay, M. G. Kutty, O. Timpe, M. Behrens, and S. B. A. Hamid, "Spectrophotometric determination of mercury with Iodide and Rhodamine B," Sains Malaysiana, vol. 41, no. 2, pp. 213-218, 2012.

[15] R. R. Gonte, K. Balasubramanian, P. C. Deb, and P. Singh, "Synthesis and characterization of mesoporous hypercrosslinked poly(styrene co-maleic anhydride) microspheres," International Journal of Polymeric Materials and Polymeric Biomaterials, vol. 61, no. 12, pp. 919-930, 2012.

[16] K. Anoop Krishnan and T. S. Anirudhan, "Removal of mercury(II) from aqueous solutions and chlor-alkali industry effluent by steam activated and sulphurised activated carbons prepared from bagasse pith: kinetics and equilibrium studies," Journal of Hazardous Materials, vol. 92, no. 2, pp. 161-183, 2002.

[17] R. Gonte and K. Balasubramanian, "Heavy and toxic metal uptake by mesoporous hypercrosslinked SMA beads: isotherms and kinetics," Journal of Saudi Chemical Society, 2013.

[18] I. Langmuir, "The constitution and fundamental properties of solids and liquids. Part I. Solids," The Journal of the American Chemical Society, vol. 38, no. 11, pp. 2221-2295, 1916.

[19] O. Abdelwahab, "Kinetic and isotherm studies of copper (II) removal from wastewater using various adsorbents," Egyptian Journal of Aquatic Research, vol. 33, no. 1, pp. 125-143, 2007. 
[20] S. Rengaraj, J.-W. Yeon, Y. Kim, Y. Jung, Y.-K. Ha, and W.-H. $\mathrm{Kim}$, "Adsorption characteristics of $\mathrm{Cu}(\mathrm{II})$ onto ion exchange resins $252 \mathrm{H}$ and $1500 \mathrm{H}$ : kinetics, isotherms and error analysis," Journal of Hazardous Materials, vol. 143, no. 1-2, pp. 469-477, 2007.

[21] A. Mittal, L. Kurup, and J. Mittal, "Freundlich and Langmuir adsorption isotherms and kinetics for the removal of Tartrazine from aqueous solutions using hen feathers," Journal of Hazardous Materials, vol. 146, no. 1-2, pp. 243-248, 2007. 

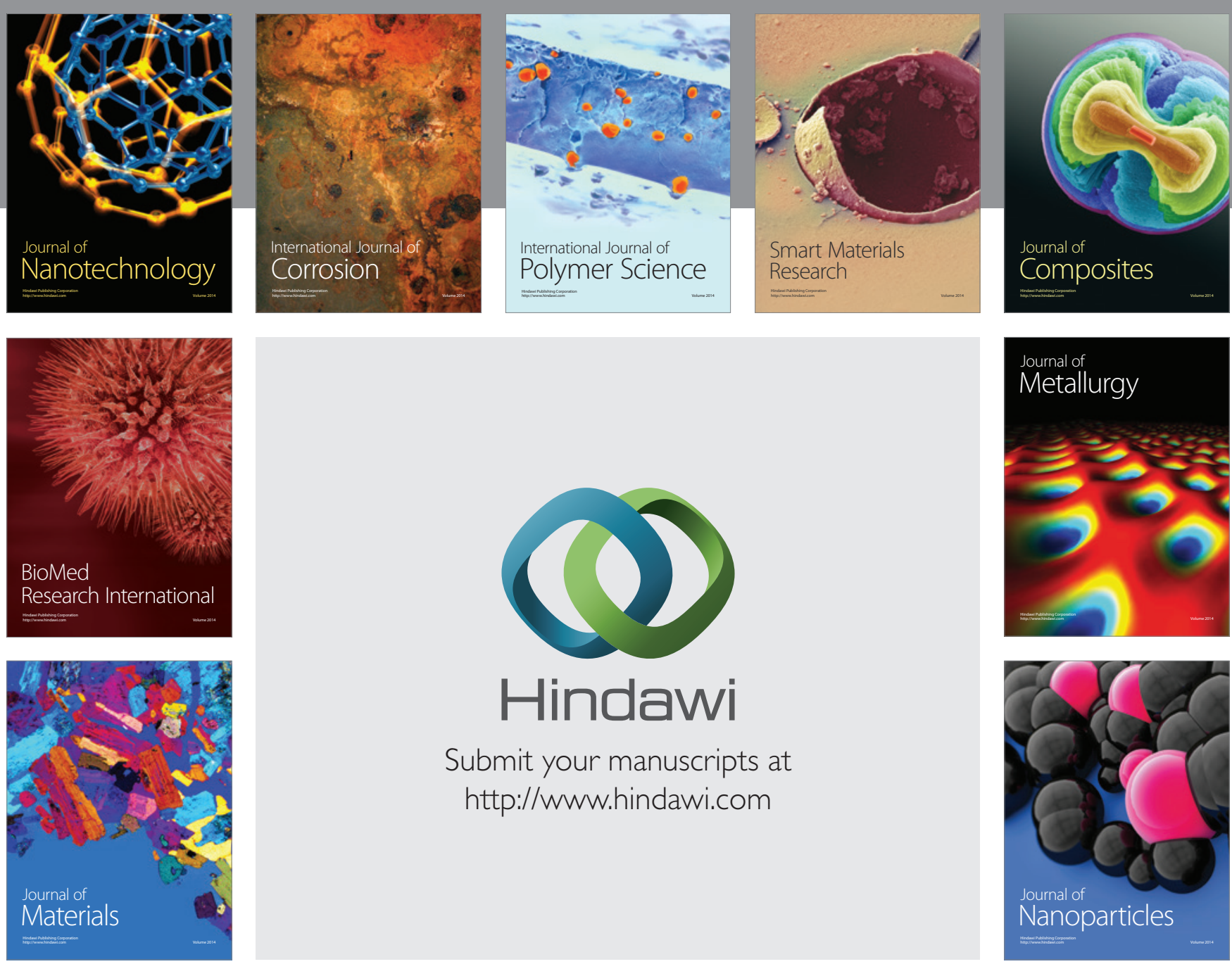

Submit your manuscripts at http://www.hindawi.com
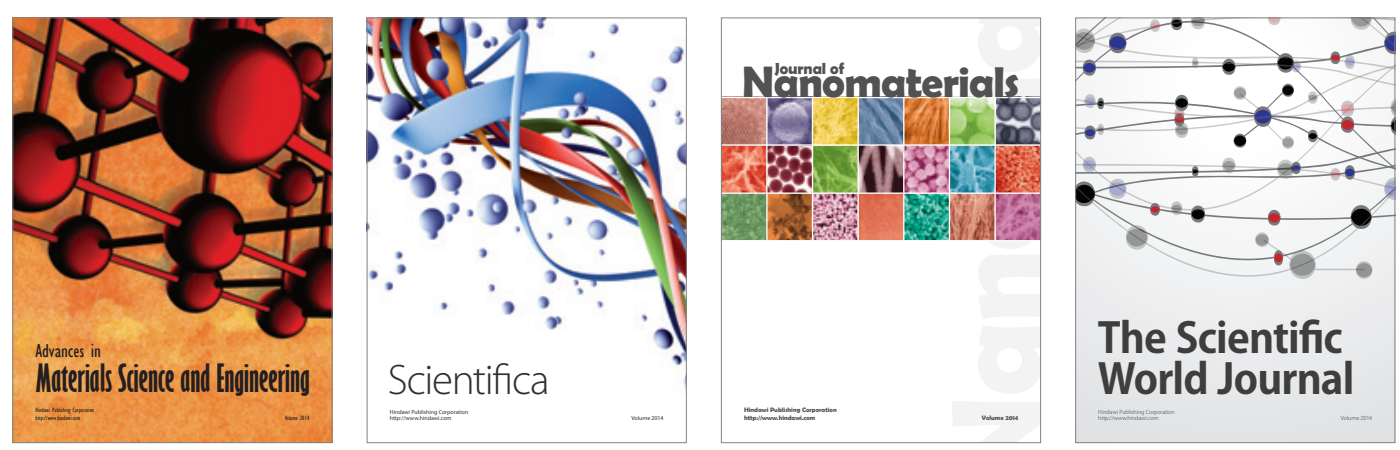

\section{The Scientific World Journal}
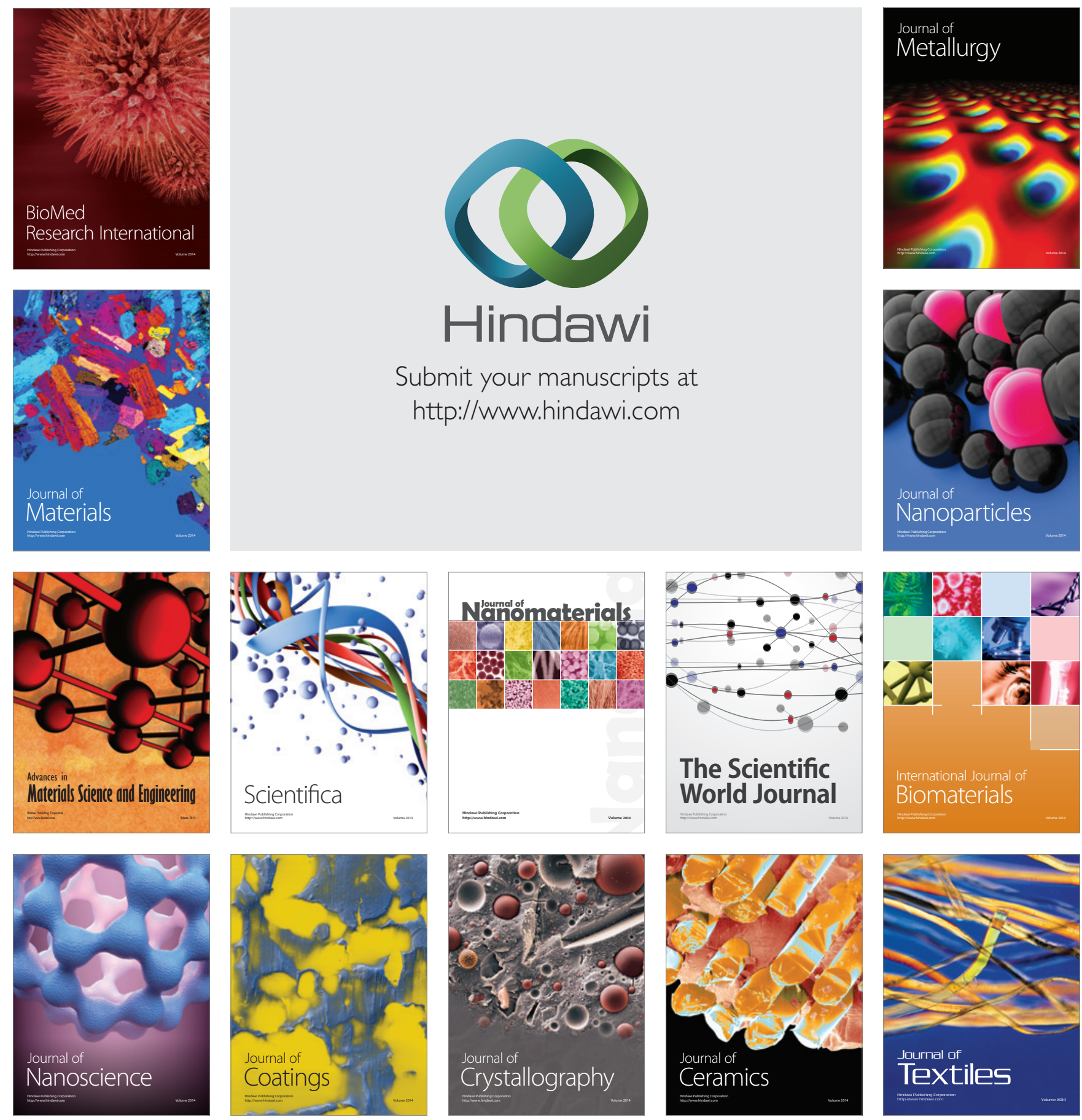